\title{
DONATO, ARTE MENOR
}

\section{Sobre as partes da oração}

As partes da oração $0^{2}$ são quantas? Oito. Quais? Nome, pronome, verbo, advérbio, particípio, conjunção, preposição e interjeição.

\section{Sobre o nome}

Nome é o quê? É a parte da oração com caso que significa um corpo ou uma ideia ${ }^{3}$ de modo próprio ou comum.

O nome tem quantos acidentes? ${ }^{4}$ Seis. Quais? Qualidade, comparação, gênero, número, figura e caso.

1 Élio Donato foi gramático da cidade de Roma em meados do século IV. A parte técnica de sua obra gramatical é um conjunto formado pela Ars minor, cuja tradução é aqui apresentada, seguida da Ars maior, organizada em três livros que tratam, respectivamente, das noções elementares de leitura e escrita, da análise e classificação dos componentes da oração e, por fim, dos desvios de linguagem em relação à norma padrão. A tradução completa das duas Artes, acompanhada de um estudo sobre a gênese da doutrina das partes da oração, encontra-se em minha dissertação de mestrado (DezotTi, Lucas C. 'Arte menor' e 'Arte maior' de Donato. São Paulo: FFLCH/USP, 2011). A edição do texto latino utilizada foi a de Louis Holtz (cf. HOLTZ, L. Donat et la tradition de l'enseignement grammatical. Paris: CNRS, 1981).

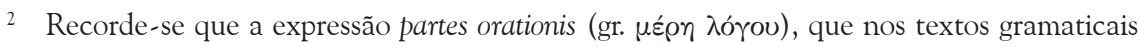
designa as classes de palavras, também comparece em textos retóricos para designar as partes ou seções de um discurso político (quais sejam: exórdio, narração, argumentação, peroração). Isso é possível porque o termo oratio, assim como seu correlato grego $\lambda o ́ \gamma o \varsigma$, serve para designar qualquer sequência linguística com significado completo, compreendendo desde uma afirmação simples como "é dia" até um texto inteiro, como um discurso oratório ou toda a Ilíada.

3 No original, rem. A grande maioria dos gramáticos latinos apresenta a oposição entre res corporales ("coisas corpóreas") e res incorporales ("coisas incorpóreas"). Donato é o primeiro a testemunhar essa oposição em outros termos (corpus aut rem), aproximando-se da formulação grega $(\sigma \tilde{\omega} \mu \alpha \hat{\eta} \pi \rho \tilde{\alpha} \gamma \mu \alpha)$ e restringindo o sentido de res como equivalente a res incorporalis, definida como "o que não é visto nem tocado, como a piedade" (SÉRvio 4.406.30) ou "o que é percebido apenas pelo intelecto" (CARísio 194.1).

4 Embora a noção de acidente não seja explicada por nenhum gramático, pode-se perceber que ela deriva da ontologia. Para Aristóteles, acidente ( $\sigma \nu \mu \beta \varepsilon \beta \eta x o ́ \varsigma)$ diz respeito a tudo o 
A qualidade dos nomes em que consiste? Em dois tipos, pois ou é nome de um só e se chama próprio ou é de muitos e se chama apelativo. ${ }^{5}$

Os graus de comparação são quantos? Três. Quais? Positivo, como doctus; comparativo, como doctior; superlativo, como doctissimus. Que nomes são comparados? Somente os apelativos que significam qualidade ou quantidade: qualidade, como bonus, malus; quantidade, como magnus, paruus. O grau comparativo depende de que caso? Do ablativo sem preposição, pois dizemos doctior illo. E o superlativo, de qual? Do genitivo plural apenas, pois dizemos doctissimus poetarum. ${ }^{6}$

Os gêneros dos nomes são quantos? Quatro. Quais? Masculino, como hic magister; feminino, como haec Musa; neutro, como hoc scamnum; comum, como hic e haec sacerdos. Há ainda o de três gêneros, chamado de universal, como hic e haec e hoc felix, e também o epiceno, isto é, indistinto, como passer, aquila.?

Os números dos nomes são quantos? Dois. Quais? Singular, como hic magister; plural, como hi magistri. ${ }^{8}$

As figuras dos nomes são quantas? Duas. Quais? Simples, como decens, potens; composta, como indecens, inpotens. Os nomes se compõem de quantos modos? Quatro: de duas partes íntegras, como suburbanus; de duas corrompidas, como efficax, municeps; de íntegra e corrompida, como insulsus; de corrompida e íntegra, como nugigerulus; às vezes de mais partes, como inexpugnabilis, inperterititus. ${ }^{9}$

que é inerente a algo sem ser uma parte dele - pois não pode ser separado daquilo em que está - nem poder ser afirmado dele - por não corresponder à sua substância (oủoí $\alpha$ ) (cf. Categorias 1.a.20-8). Os estoicos apoiaram nessa teoria a ideia da permanência do ser de uma palavra, enquanto sua aparência sensível se modifica em função da cadeia falada. É bastante provável que os gramáticos tenham desenvolvido seus sistemas de classificação a partir do esquema estoico (cf. HolTz 1981:68-9).

5 Oposição que em grande medida corresponde à atual entre substantivo próprio e substantivo comum; convém notar, porém, que os nomes apelativos também incluem os adjetivos da classificação atual.

6 Os exemplos se traduzem, respectivamente, por: "douto", "mais douto", "o mais douto"; "bom", "mau"; "grande", "pequeno"; "mais douto que ele"; "o mais douto dos poetas".

7 Os exemplos se traduzem, respectivamente, por: "o professor"; "a musa”; "o banco"; "o sacerdote e a sacerdotiza"; "o, a, isso fértil”; "pardal”, "águia”. (Um exemplo de gênero comum em português poderia ser "o e a artista".)

8 Os exemplos se traduzem, respectivamente, por: "o professor"; "os professores".

9 Os exemplos se traduzem, respectivamente, por: "decente", "potente"; "indecente", "impotente"; "suburbano" (de sub+urbanus, "que fica perto da cidade"); "eficaz" (de ex+faciens, "o que faz totalmente"), "munícipe" (de munus+capiens, "o que assume 
Os casos dos nomes são quantos? Seis. Quais? Nominativo, genitivo, dativo, acusativo, vocativo e ablativo. Por meio deles, nomes, pronomes e particípios de todos os gêneros são declinados do seguinte modo:

Magister, nome apelativo de gênero masculino, número singular, figura simples, casos nominativo e vocativo, que será declinado assim: ${ }^{10}$

$\begin{aligned} \text { nominativo } & \text { hic magister }{ }^{10} & \text { e no plural, nominativo } & \text { hi magistri } \\ \text { genitivo } & \text { huius magistri } & \text { genitivo } & \text { horum magistrorum } \\ \text { dativo } & \text { huic magistro } & \text { dativo } & \text { his magistris } \\ \text { acusativo } & \text { hunc magistrum } & \text { acusativo } & \text { hos magistros } \\ \text { vocativo } & \text { o magister } & \text { vocativo } & \text { o magistri } \\ \text { ablativo } & \text { ab hoc magistro } & \text { ablativo } & \text { ab his magistris. }\end{aligned}$

Musa, nome apelativo de gênero feminino, número singular, figura simples, casos nominativo e vocativo, que será declinado assim:

$\begin{aligned} \text { nominativo } & \text { haec Musa } \\ \text { genitivo } & \text { huius Musae } \\ \text { dativo } & \text { huic Musae } \\ \text { acusativo } & \text { hanc Musam } \\ \text { vocativo } & \text { o Musa } \\ \text { ablativo } & \text { ab hac Musa }\end{aligned}$

$\begin{aligned} \text { e no plural, nominativo } & \text { hae Musae } \\ \text { genitivo } & \text { harum Musarum } \\ \text { dativo } & \text { his Musis } \\ \text { acusativo } & \text { has Musas } \\ \text { vocativo } & \text { o Musae } \\ \text { ablativo } & \text { ab his Musis. }\end{aligned}$

uma função pública"); "insosso" (de in+salsus, "não salgado"), "quinquilheiro" (de nugas + gerulus, "vendedor de bugigangas"); "inexpugnável" (de in +ex+pugnabilis, "que não pode ser totalmente abatido"), "impávido" (de in+per+territus, "que absolutamente não fica apavorado").

10 Note que existe uma ordem regular para enunciar as propriedades acidentais da palavra que serve de exemplo para a declinação; essa ordem é a mesma da apresentação dos acidentes. Isso constitui um indício de que o curso do gramático não pretende ensinar uma língua, mas uma ciência da linguagem. Nesse sentido, quando o mestre lhe faz recitar uma declinação, é menos para controlar as formas corretas, e mais para verificar se ele assimilou adequadamente o método de análise (cf. Holtz 1981: 107-8).

11 Observe o emprego do pronome demonstrativo na função de artigo, provavelmente como fator de redundância positiva para os acidentes (cf. pronome articular, adiante). Recorde-se, ademais, da definição estoica de artigo, como aquele "que determina os gêneros e os números dos nomes" (DióGenes LaÉRCIO 7.58). 
Scamnum, nome apelativo de gênero neutro, número singular, figura simples, casos nominativo, acusativo e vocativo, que será declinado assim:

$\begin{aligned} \text { nominativo } & \text { hoc scamnum } \\ \text { genitivo } & \text { huius scamni } \\ \text { dativo } & \text { huic scamno } \\ \text { acusativo } & \text { hoc scamnum } \\ \text { vocativo } & \text { o scamnum } \\ \text { ablativo } & \text { ab hoc scamno }\end{aligned}$

$\begin{aligned} \text { e no plural, nominativo } & \text { haec scamna } \\ \text { genitivo } & \text { horum scamnorum } \\ \text { dativo } & \text { his scamnis } \\ \text { acusativo } & \text { haec scamna } \\ \text { vocativo } & \text { o scamna } \\ \text { ablativo } & \text { ab his scamnis. }\end{aligned}$

Sacerdos, nome apelativo de gênero comum, número singular, figura composta, casos nominativo e vocativo, que será declinado assim:

$\begin{aligned} \text { nominativo } & \text { hic e haec sacerdos } & \text { e no plural, nominativo } & \text { hi e hae sacerdotes } \\ \text { genitivo } & \text { huius sacerdotis } & \text { genitivo } & \text { horum e harum sacerdotum } \\ \text { dativo } & \text { huic sacerdoti } & \text { dativo } & \text { his sacerdotibus } \\ \text { acusativo } & \text { hunc e hanc sacerdotem } & \text { acusativo } & \text { hos e has sacerdotes } \\ \text { vocativo } & \text { o sacerdos } & \text { vocativo } & \text { o sacerdotes } \\ \text { ablativo } & \text { ab hoc e ab hac sacerdote } & \text { ablativo } & \text { ab his sacerdotibus. }\end{aligned}$

Felix, nome apelativo de gênero universal, número singular, figura simples, casos nominativo e vocativo, que será declinado assim:
nom. hic e haec e hoc felix
e no plural, nom. hi e hae felices e haec felicia
gen. huius felicis
gen. horum e harum e horum felicium
dat. huic felici
dat. his felicibus
acus. hunc e hanc felicem e hoc felix
acus. hos e has felices e haec felicia
voc. of felix
abl. ab hoc e ab hac e ab hoc felice ou felici
voc. o felices e o felicia
abl. ab his felicibus.

Todo nome que, no caso ablativo singular, termina em - a ou -o, faz o genitivo plural em quê? Em -rum, e o dativo e o ablativo em -is.

Todo nome que, no caso ablativo singular, termina em -e, -i ou -u, faz o genitivo plural em quê? Se for -e breve, em -um; se for -e longo, em -rum; se for -i, em -ium; se for -u, em -uum, com a letra u duplicada. E o dativo e o ablativo, faz em quê? Todos em -bus. 


\section{Sobre o pronome}

Pronome é o quê? É a parte da oração que, empregada no lugar do nome, significa quase o mesmo e às vezes traz ${ }^{12}$ a pessoa. O pronome tem quantos acidentes? Seis. Quais? Qualidade, gênero, número, figura, pessoa e caso.

A qualidade dos pronomes em que consiste? Em dois tipos, pois os pronomes são definidos ou indefinidos. Quais são definidos? Os que trazem as pessoas, como ego, tu, ille. Quais são indefinidos? Os que não trazem as pessoas, como quis quae quod. ${ }^{13}$

Os gêneros dos pronomes quais são? Praticamente os mesmos que os dos nomes: masculino, como quis; feminino, como quae; neutro, como quod; comum, como qualis, talis; de três gêneros, como ego, tu. ${ }^{14}$

Os números dos pronomes são quantos? Dois. Quais? Singular, como hic; plural, como hi. ${ }^{15}$

As figuras dos pronomes são quantas? Duas. Quais? Simples, como quis; composta, como quisquis. ${ }^{16}$

As pessoas dos pronomes são quantas? Três. Quais? Primeira, como ego; segunda, como tu; terceira, como ille.

E os casos dos pronomes, são quantos? Seis, como os dos nomes, por meio dos quais os pronomes de todos os gêneros se flexionam do seguinte modo:

Ego, pronome definido, de gênero universal, número singular, figura simples, primeira pessoa, caso nominativo, que será declinado assim:

$$
\begin{array}{llllll} 
& \text { ego mei ou mis mihi me a me } & \\
\text { e no plural nos nostrum ou nostri nobis nos } 0 \text { a nobis }
\end{array}
$$

- da segunda pessoa, gênero universal, número singular:

12 No original, recipit. De acordo com a doutrina dos acidentes, se estes sobrevêm às substâncias (isto é, às palavras), estas por sua vez "recebem", "acolhem" os acidentes.

13 Pronomes definidos são os que indicam uma pessoa determinada: "quando alguém diz ego, o pronome representa sem dúvida a pessoa que falou" (POMPEIO 5.202.20); indefinidos são os que não definem por si a pessoa de que se trata, podendo se referir a qualquer uma das pessoas indistintamente, como quis (cf. [SÉrGIO] 4.500.6-12). Os exemplos se traduzem, respectivamente, por: "eu”, "tu”, "ele"; "quem/que" (nos três gêneros).

14 Os exemplos se traduzem, respectivamente, por: "quem/que" (nos três gêneros); "qual", "tal"; "eu", "tu".

15 Os exemplos se traduzem, respectivamente, por: "este"; "estes".

16 Os exemplos se traduzem, respectivamente, por: "quem"; "quem quer que seja". 
$\begin{array}{ll} & \text { tu tui ou tis tibi te } 0 \text { a te } \\ \text { e no plural uos uestrum ou vestri uobis uos } 0 \text { a uobis }\end{array}$

- da terceira pessoa, gênero masculino, número singular:

ille illius illi illum 0 abillo

e no plural illi illorum illis illos 0 ab illis

gênero feminino, número singular:

illa illius illi illam 0 ab illa

e no plural illae illarum illis illas 0 abillis

gênero neutro, número singular:

illud illius illi illud 0 ab illo

e no plural illa illorum illis illa 0 abillis.

Menos-que-definido, do gênero masculino, número singular: ${ }^{17}$

ipse ipsius ipsi ipsum 0 abipso

e no plural ipsi ipsorum ipsis ipsos 0 abipsis

gênero feminino, número singular:

ipsa ipsius ipsi ipsam 0 ab ipsa

e no plural ipsae ipsarum ipsis ipsas 0 abipsis

do gênero neutro, número singular:

ipsum ipsius ipsi ipsum 0 ab ipso

e no plural ipsa ipsorum ipsis ipsa 0 ab ipsis

Menos-que-definido, do gênero masculino, número singular: ${ }^{18}$

iste istius isti istum 0 ab isto

e no plural isti istorum istis istos 0 ab istis

gênero feminino, número singular:

ista istius isti istam 0 ab ista

e no plural istae istarum istis istas 0 ab istis

gênero neutro, número singular:

istud istius isti istud 0 ab isto

e no plural ista istorum istis ista 0 ab istis

17 Pronomes menos-que-definidos são uma espécie de indefinidos, assim chamados porque, embora possam se associar a qualquer uma das três pessoas, representam uma pessoa definida no contexto da enunciação, como ipse ("o próprio"). A lista dos menos-quedefinidos é constituída por seis pronomes, que se distinguem em duas subespécies: os que significam pessoas ausentes (is, idem, ipse) e os que significam pessoas presentes (iste, hic); o sexto é o reflexivo sui.

18 Os exemplos a seguir se traduzem, respectivamente, por: "esse", "essa”, "isso". 
Prepositivo articular ou demonstrativo, do gênero masculino, número singular: ${ }^{19}$

hic huivs huic hunc 0 abhoc

e no plural hi horum his hos 0 ab his

gênero feminino, número singular:

haec huius huic hanc 0 abhac

e no plural hae harum his has 0 abhis

gênero neutro, número singular:

hoc huivs huic hoc 0 abhoc

e no plural haec horum his haec 0 abhis

Pospositivo ou relativo, do gênero masculino, número singular: ${ }^{20}$

is eius ei eum 0 abeo

e no plural ei eorum eis eos 0 abeis

gênero feminino, número singular:

ea eius ei eam 0 ab ea

e no plural eae earum eis eas 0 abeis

gênero neutro, número singular:

id eius ei id 0 abeo

e no plural ea eorum eis ea 0 abeis

Indefinidos, do gênero masculino, número singular: ${ }^{21}$

quis cuius cui quem 0 a quo ou a qui

e no plural qui quorum quis ou quibus quos 0 a quis ou a quibus

gênero feminino, número singular:

quae cuius cui quam 0 a qua ou a qui
e no plural quae quarum quis ou quibus quas 0 a quis ou a quibus

gênero neutro, número singular:

quod cuius cui quod o a quo ou a qui

e no plural quae quorum quis ou quibus quae 0 a quis ou a quibus

19 Refere-se à demonstração, referindo-se à primeira menção a alguma coisa; por esse motivo, o pronome vem antes (praeponitur), daí ser também chamado de prepositivo (PRISCIANO 2.579.16-9). Por se declinar frequentemente junto ao nome, funcionando como o artigo grego, é qualificado como articular (SÉRVIO 4.410.14-7. Os exemplos a seguir podem se traduzir ou como artigo (“o”, "a”, "o” neutro), ou como demonstrativos ("este”, "esta”, "isto”).

20 Relativo no sentido de fazer referência, chamados em grego de anafóricos. A referência (relatio) consiste na segunda menção a alguma coisa; por esse motivo, o pronome vem depois (subiungitur), daí ser também chamado de pospositivo (subiunctiuum).

21 Consideram-se indefinidos sete pronomes: quis, qualis, talis, quantus, tantus, quotus, totus (POMPEIO 5.201.32-3). 
Possessivos definidos em relação a algo, com as duas partes no singular, do gênero masculino:22

meus mei meo meum 0 a meo

e com a segunda parte no plural:

mei meorum meis meos 0 a meis

gênero feminino, número singular:

mea meae meae meam 0 a mea

e no plural meae mearum meis meas 0 a meis

gênero neutro, número singular:

meum mei meo meum 0 a meo

e no plural mea meorum meis mea 0 a meis

- da segunda pessoa, gênero masculino, número singular:

tuus tui tuo tuum 0 a tuo

e no plural tui tuorum tuis tuos 0 a tuis

gênero feminino, número singular:

tua tuae tuae tuam 0 a tua

e no plural tuae tuarum tuis tuas 0 a tuis

gênero neutro, número singular:

tuum tui tuo tuum 0 a tuo

e no plural tua tuorum tuis tua 0 a tuis

- da terceira pessoa, gênero masculino, número singular:

suus sui suo suum 0 a suo
e no plural sui suorum suis suos 0 a suis
gênero feminino, número singular:
sua suae suae suam 0 a sua
e no plural suae suarum suis suas 0 a suis
gênero neutro, número singular:
suum sui suo suum 0 a suo
e no plural sua suorum suis sua 0 a suis

22 Os possessivos são a espécie de indefinidos que indicam que alguém possui alguma coisa. São ditos "em relação a algo" (ad aliquid) porque, assim como certos nomes e particípios, só adquirem significado quando dizem respeito a alguma coisa, não podendo ser entendidos se estiverem sozinhos; de fato, a existência de um possuidor implica necessariamente algo que é possuído (CARísio 200.24-5). Daí a referência, na declinação, a "duas partes" que se flexionam em número: a intrínseca, do possuidor, e a extrínseca, da coisa possuída (SÉRVIO 4.410.17). Os exemplos a seguir se traduzem por "meu", "minha”, "meu” (n.); "teu”, "tua”, "teu” (n.); "seu”, "sua”, "seu” (n.); "nosso", "nossa”,"nosso" (n.); "vosso", "vossa”, "vosso” (n.). 
Possessivos definidos em relação a algo, com a primeira parte no plural, do gênero masculino:

$$
\text { noster nostri nostro nostrum } 0 \text { a nostro }
$$

e com as duas partes no plural:

$$
\text { nostri nostrorum nostris nostros } 0 \text { a nostris }
$$

gênero feminino, número singular:

nostra nostrae nostrae nostram 0 a nostra

e no plural nostrae nostrarum nostris nostras 0 a nostris

gênero neutro, número singular:

$$
\text { nostrum nostri nostro nostrum } 0 \text { a nostro }
$$

e no plural nostra nostrorum nostris nostra 0 a nostris

- da segunda pessoa, gênero masculino, número singular:

vester vestri uestro vestrum 0 a uestro

e no plural vestri vestrorum vestris vestros 0 a vestris

gênero feminino, número singular:

vestra vestrae vestrae vestram 0 a uestra

e no plural vestrae vestrarum vestris vestras 0 a vestris

gênero neutro, número singular:

vestrum vestri vestro vestrum 0 a vestro

e no plural vestra vestrorum vestris vestra 0 a vestris

Cite compostos desses. Egomet, tute, illic, istic, idem - que com i longo é masculino, com i breve é neutro -, quisquis, quisnam, quispiam, aliquis, etc. ${ }^{23}$

\section{Sobre o verbo}

Verbo é o quê? É a parte da oração com tempo e pessoa, sem caso, que significa fazer algo ou ser afetado, ou nenhum dos dois. $O$ verbo tem quantos acidentes? Sete. Quais? Qualidade, conjugação, gênero, número, figura, tempo e pessoa.

A qualidade dos verbos em que consiste? Em modos e formas. Quais são os modos? Indicativo, como lego; imperativo, como lege; optativo, como utinam legerem; conjuntivo, como cum legam; infinitivo, como legere; impessoal, como legitur. ${ }^{24}$ As formas

23 Os exemplos de pronomes compostos podem ser traduzidos, respectivamente, por: "eu mesmo", "tu mesmo”, "ele aî", "esse aî”, "ele mesmo”, “quem quer que seja”, "mas quem...?", "um qualquer", "alguém”.

24 Os exemplos de modos verbais se traduzem, respectivamente, por: "leio"; "lê"; "quem dera eu lesse"; "desde que eu leia"; "ler"; "lê-se". 
dos verbos são quantas? Quatro. Quais? Perfeita, como lego; meditativa, como lecturio; frequentativa, como lectito; incoativa, como fervesco, calesco. ${ }^{25}$

As conjugações dos verbos são quantas? Três. Quais? Primeira, segunda e terceira.

Qual é a primeira? Aquela que, na segunda pessoa do singular do presente do indicativo de um verbo ativo ou neutro, tem um a longo antes da última letra ou, no caso de um verbo passivo, comum ou depoente, antes da última sílaba, como amo amas, amor amaris; além disso, faz o futuro do indicativo em -bo e em -bor, como amo amabo, amor amabor. ${ }^{26}$

Qual é a segunda? Aquela que, na segunda pessoa do singular do presente do indicativo de um verbo ativo ou neutro, tem um e longo antes da última letra ou, no caso de um verbo passivo, comum ou depoente, antes da última sílaba, como doceo doces, doceor doceris; além disso, faz o futuro do indicativo em -bo e em -bor, como doceo docebo, doceor docebor. ${ }^{27}$

Qual é a terceira? Aquela que, na segunda pessoa do singular do presente do indicativo de um verbo ativo ou neutro, tem um i breve ou um i longo antes da última letra ou, no caso de um verbo passivo, comum ou depoente, tem um e breve (no lugar do i) ou um i longo antes da última sílaba, como lego legis, legor legeris, audio audis, audior audiris; além disso, faz o futuro do indicativo em -am e em -ar, como lego legam, legor legar, audio audiam, audior audiar. ${ }^{28}$ Isto - se a letra i é breve ou longa - pode ser rapidamente percebido no imperativo e no infinitivo, pois, se for breve, o i converte-se em e; se for longo, não se altera. Quando a terceira conjugação faz o futuro não só em -am mas

25 O que Donato chama de formas corresponde de perto ao que conhecemos como aspectos verbais; apesar disso, evitou-se uma atualização terminológica por se tratar provavelmente de um termo genérico, na medida em que tanto o termo forma pode se referir a outra distinção verbal (pessoal vs. impessoal, cf. SACERDOTE 6.429.20), quanto a própria distinção aspectual pode ser tratada sob rótulo diverso (species, cf. Prisciano 2.427.11). Os exemplos se traduzem, respectivamente, por: "desejo ler"; "leio muitas vezes"; "começo a ferver", "aqueço-me".

26 Os grupos de exemplos se traduzem, respectivamente, por: "amo, amas, sou amado, és amado"; "amo, amarei, sou amado, serei amado".

27 Os grupos de exemplos se traduzem, respectivamente, por: "ensino, ensinas, sou ensinado, és ensinado"; "ensino, ensinarei, sou ensinado, serei ensinado".

28 Os grupos de exemplos se traduzem, respectivamente, por: "leio, lês, sou lido, és lido; ouço, ouves, sou ouvido, és ouvido"; "leio, lerei, sou lido, serei lido; ouço, ouvirei, sou ouvido, serei ouvido". 
também em -bo? Algumas vezes, quando ela tiver a letra i longa, e não breve, como eo is ibo ou eam, queo quis quibo ou queam. ${ }^{29}$

Os gêneros dos verbos são quantos? Cinco. Quais? Ativos, passivos, neutros, depoentes e comuns.

Quais são os ativos? Aqueles que terminam em -o e que, após receber a letra $\mathrm{r}$, tornam-se passivos, como lego: legor. $^{30}$

Quais são os passivos? Aqueles que terminam em -r e que, suprimida essa letra, voltam a ser ativos, como legor: lego. ${ }^{31}$

Quais são os neutros? Aqueles que terminam em -o, como os ativos, mas que, após receber a letra -r, não existem, como sto, curro; não se diz stor, curror. ${ }^{32}$

Quais são os depoentes? Aqueles que terminam em -r, como os passivos, mas que, suprimida essa letra, não existem, como luctor, loquor. ${ }^{33}$

Quais são os comuns? Aqueles que terminam em -r, como os depoentes, mas que se aplicam às duas formas, a do paciente e a do agente, como osculor, criminor: dizemos osculor te e osculor a te, criminor te e criminor a te. ${ }^{34}$

Os números dos verbos são quantos? Dois. Quais? Singular, como lego; plural, como legimus. ${ }^{35}$

As figuras dos verbos são quantas? Duas. Quais? Simples, como lego; composta, como neglego.

29 Esses últimos exemplos se traduzem, respectivamente, por: "vou, vais, irei, irei; posso, podes, poderei, poderei".

30 Os exemplos se traduzem, respectivamente, por: "leio: sou lido".

31 Os exemplos se traduzem, respectivamente, por: "sou lido: leio".

32 Trata-se de verbos cuja ação não pode ser "invertida”, isto é, verbos que não podem transitar entre as significações ativa e passiva. Isso se expressa na impossibilidade de receberem o morfema apassivador, como se vê nos exemplos, que se traduzem, respectivamente, por: "fico", "corro" ("sou ficado" e "sou corrido" são agramaticais).

33 Os depoentes se assemelham aos passivos mas, assim como os neutros, apresentam uma única significação, ou passiva ou ativa (cf. PrISCIANO 2.378.23); os exemplos se traduzem, respectivamente, por: "luto", "falo".

34 Os exemplos se traduzem, respectivamente, por: "beijo-te, sou beijado por ti", "acuso-te, sou acusado por ti”.

35 Os exemplos se traduzem, respectivamente, por: "leio"; "lemos". 
Os tempos dos verbos são quantos? Três. Quais? Presente, como lego; pretérito, como legi; futuro, como legam. Quantos são os tempos na declinação $0^{36}$ dos verbos? Cinco. Quais? Presente, como lego; pretérito imperfeito, como legebam; pretérito perfeito, como legi; pretérito mais-que-perfeito, como legeram; futuro, como legam. ${ }^{37}$

As pessoas dos verbos são quantas? Três. Quais? Primeira, como lego; segunda, como legis; terceira, como legit. ${ }^{38}$

Dê a declinação do verbo ativo. ${ }^{39}$

Lego, verbo ativo dito no modo indicativo, tempo presente, número singular, figura simples, primeira pessoa, terceira conjugação breve, que será declinado assim: lego legis legit

e no plural legimus legitis legunt

pretérito imperfeito:

legebam legebas legebat

e no plural legebamus legebatis legebant

pretérito perfeito:

legi legisti legit

e no plural legimus legistis legerunt ou legere

pretérito mais-que-perfeito:

legeram legeras legerat

e no plural legeramus legeratis legerant

futuro:

$\begin{array}{cl} & \text { legam leges leget } \\ \text { e no plural } & \text { legemus legetis legent }\end{array}$

36 Os gramáticos latinos não faziam distinção terminológica entre a flexão dos nomes pelos casos e a flexão dos verbos pelos tempos: ambas eram consideradas "declinações", isto é, desvios da forma primitiva (respectivamente, o nominativo singular e a primeira pessoa do presente do indicativo); Varrão usa declinare também para o processo de derivação (cf. De lingua latina 8.14).

37 Os exemplos se traduzem, respectivamente, por: "leio", "li", "lerei"; "leio", "lia", "li", "lera", "lerei".

38 Os exemplos se traduzem, respectivamente, por: "leio", "lês", "lê".

39 A formulação com o imperativo sugere que o modo de estruturação da Arte menor em perguntas e respostas simula uma situação de sala de aula, indicando o que o professor deve solicitar de seus alunos e como estes devem responder (cf. Holtz 1981: 102). Porém, isso não quer dizer que o interlocutor ideal do tratado seja o estudante; na verdade, a Arte menor parece ser muito mais um material produzido para o professor, consistindo numa espécie de roteiro para a verificação oral do conhecimento do aluno. 
- no modo imperativo, tempo presente, para a segunda e a terceira pessoa:

lege legat

e no plural legamus legite legant

futuro:

legito legito

e no plural legamus legitote legant ou legunto

- no modo optativo, tempos presente e pretérito imperfeito:

utinam legerem legeres legeret

e no plural utinam legeremus legeretis legerent

pretérito perfeito e mais-que-perfeito:

utinam legissem legisses legisset

e no plural utinam legissemus legissetis legissent

futuro:

utinam legam legas legat

e no plural utinam legamus legatis legant

- no modo conjuntivo, tempo presente:

cum legam legas legat

e no plural cum legamus legatis legant

pretérito imperfeito:

cum legerem legeres legeret

e no plural cum legeremus legeretis legerent

pretérito perfeito:

cum legerim legeris legerit

e no plural cum legerimus legeritis legerint

pretérito mais-que-perfeito:

cum legissem legisses legisset

e no plural cum legissemus legissetis legissent

futuro:

cum legero legeris legerit

e no plural cum legerimus legeritis legerint.

- no modo infinitivo ${ }^{40}$ em número e pessoa:

tempo presente legere

pretérito legisse

futuro lectum ire ou lecturum esse

40 No original, infinitum, i.e. "indefinido". Compare com a definição de pronome indefinido (infinitum pronomen), acima. 
- o verbo impessoal:

no tempo presente legitur

pretérito imperfeito legebatur

pretérito perfeito lectum est ou lectum fuit

pretérito mais-que-perfeito lectum erat ou lectum fuerat

futuro legetur

- os verbos gerundiais ou participiais são estes:

legendi legendo legendum lectum lectu

- dois particípios são tirados do verbo ativo, um do tempo presente e um do futuro: do presente, legens; do futuro, lecturus.

Legor, verbo passivo dito no modo indicativo, tempo presente, número singular, figura simples, primeira pessoa, terceira conjugação breve, que será declinado assim:

legor legeris ou legere legitur

e no plural legimur legimini leguntur

pretérito imperfeito:

legebar legebaris ou legebare legebatur

e no plural legebamur legebamini legebantur

pretérito perfeito:

lectus sum es est

e no plural lecti sumus estis sunt

e no modo de anterioridade:

lectus fui fuisti fuit

e no plural lecti fuimus fuistis fuerunt ou fuere

pretérito mais-que-perfeito:

lectus eram eras erat

e no plural lecti eramus eratis erant

e no modo de anterioridade:

lectus fueram fueras fuerat

e no plural lecti fueramus fueratis fuerant

futuro:

legar legeris ou legere legetur

e no plural legemur legemini legentur

- no modo imperativo, tempo presente, para a segunda e a terceira pessoa: legere legatur

e no plural legamur legimini legantur 
futuro:

$\begin{array}{cll} & \text { legitor } & \text { legitor } \\ \text { e no plural } & \text { legamur } & \text { legiminor leguntor }\end{array}$

- no modo optativo, tempos presente e pretérito imperfeito:

utinam legerer legereris ou legerere legeretur

e no plural utinam legeremur legeremini legerentur

pretérito perfeito e mais-que-perfeito:

utinam lectus essem esses esset

e no plural utinam lecti essemus essetis essent

e no modo de anterioridade:

utinam lectus fuissem fuisses fuisset

e no plural utinam lecti fuissemus fuissetis fuissent

futuro:

utinam legar legaris ou legare legatur

e no plural utinam legamur legamini legantur

- no modo conjuntivo, tempo presente:

cum legar legaris ou legare legatur

e no plural cum legamur legamini legantur

pretérito imperfeito:

cum legerer legereris ou legerere legeretur

e no plural cum legeremur legeremini legerentur

pretérito perfeito:

cum lectus sim sis sit

e no plural cum lecti simus sitis sint

e no modo de anterioridade:

cum lectus fuerim fueris fuerit

e no plural cum lecti fuerimus fueritis fuerint

pretérito mais-que-perfeito:

cum lectus essem esses esset

e no plural cum lecti essemus essetis essent

e no modo de anterioridade:

cum lectus fuissem fuisses fuisset

e no plural cum lecti fuissemus fuissetis fuissent

futuro:

cum lectus ero eris erit

e no plural cum lecti erimus eritis erint 
e no modo de anterioridade:

cum lectus fuero fueris fuerit

e no plural cum lecti fuerimus fueritis fuerint.

- no modo infinitivo em número e pessoa:

tempo presente legi

pretérito perfeito lectum esse ou fuisse

futuro lectum iri

- dois particípios são tirados do verbo passivo, um do tempo pretérito e um do futuro: do pretérito, lectus; do futuro, legendus.

O verbo neutro segue a regra do ativo; o comum e o depoente, a regra do passivo.

\section{Sobre o advérbio}

Advérbio é o quê? É a parte da oração que, colocada junto do verbo, esclarece e completa a significação dele. O advérbio tem quantos acidentes? Três. Quais? Significação, comparação e figura.

A significação dos advérbios em que consiste? É que há advérbios de lugar, de tempo, de número, de negação, de afirmação, de demonstração, de desejo, de exortação, de ordem, de interrogação, de semelhança, de qualidade, de quantidade, de dúvida, pessoais, de interpelação, de resposta, de separação, de juramento, de escolha, de reunião, de proibição, de eventualidade, de comparação.

Dê advérbios: ${ }^{41}$

- de lugar, como hic, ibi, intus, foris, ilic, inde

- de tempo, como hodie, nuper, aliquando

- de número, como semel, bis

- de negação, como non

- de afirmação, como etiam, quidni

- de demonstração, como en, ecce

41 Os exemplos a seguir se traduzem, respectivamente, por: "aqui”, “aî”, "dentro”, "fora”, "lá”, "daî”; "hoje”, "recentemente”, "outrora”; "uma vez”, "duas vezes”; "não”; “certamente”, "por que não?”; “eis”, “aqui está”; “oxalá”; “vai!”; “em seguida”; "por quê?”, "por que razão?”, "por que motivo?”; “como se”, "bem como”; “doutamente”, "lindamente”; "muito", "pouco"; "talvez”, "provavelmente”; “comigo”, "contigo”, "consigo”, “conosco”, “convosco”; “ei!”; “oi!”; “separadamente”; "por Pólux!”, “por Cástor!”, “por Hércules!", "pelo deus da verdade!”; "de preferência”, "ou melhor”; "ao mesmo tempo”, "juntamente"; "não!”; “casualmente”, "fortuitamente”; "mais”, "tão”. Sobre o significado do imperativo, cf. n. 39. 
- de desejo, como utinam

- de exortação, como eia

- de ordem, como deinde

- de interrogação, como cur, quare, quamobrem

- de semelhança, como quasi, ceu

- de qualidade, como docte, pulchre

- de quantidade, como multum, parum

- de dúvida, como forsitan, fortasse

- pessoais, como mecum, tecum, secum, nobiscum, uobiscum

- de interpelação, como heus

- de resposta, como heu

- de separação, como seorsum

- de juramento, como edepol, ecastor, hercle, medius fidius

- de escolha, como potius, immo

- de reunião, como simul, una

- de proibição, como ne

- de eventualidade, como forte, fortuitu

- de comparação, como magis, tam.

A comparação dos advérbios em que consiste? Em três graus de comparação: positivo, comparativo e superlativo. Cite um advérbio do grau positivo, como docte; do comparativo, como doctius; do superlativo, como doctissime..$^{42}$ Não dizemos magis doctius nem tam doctissime, porque magis e tam se juntam apenas ao grau positivo, muito embora os antigos tenham dito tam magis e quam magis.

As figuras dos advérbios são quantas? Duas. Quais? Simples e composta: simples, como docte, prudenter; composta, como indocte, inprudenter. ${ }^{43}$

Os advérbios de lugar são no lugar, do lugar ou para o lugar. Porém, os advérbios no lugar e os advérbios do lugar têm a mesma significação, como intus sum, intus exeo, foris sum, foris uenio, enquanto os advérbios para o lugar têm outra significação, como intro eo, foras eo. ${ }^{44}$ Porém, não dizemos de intus nem de foris, bem como ad foras ou in foras.

42 Os exemplos se traduzem por: "doutamente"; "mais doutamente"; "muito doutamente".

43 Os exemplos se traduzem por: "doutamente", "prudentemente"; "indoutamente", "imprudentemente".

44 Veja que aqui significatio diz respeito à forma significante. Os exemplos se traduzem, respectivamente, por: "estou dentro", "saio de dentro", "estou fora", "venho de fora"; "vou para dentro", "vou para fora". 


\section{Sobre o particípio}

Particípio é o quê? É a parte da oração que traz $z^{45}$ parte de nome e parte de verbo: de nome, gêneros e casos; de verbo, tempos e significações; de ambos, número e figura. O particípio tem quantos acidentes? Seis. Quais? Gêneros, casos, tempos, significações, número e figura.

Os gêneros dos particípios são quantos? Quatro. Quais? Masculino, como hic lectus; feminino, como haec lecta; neutro, como hoc lectum; comum aos três gêneros, como hic e haec e hoc legens. ${ }^{46}$

Os casos dos particípios são quantos? Seis. Quais? Nominativo, como hic legens; genitivo, como huius legentis; dativo, como huic legenti; acusativo, como hunc legentem; vocativo, como o legens; ablativo, como ab hoc legente.

Os tempos dos particípios são quantos? Três. Quais? Presente, como legens; pretérito, como lectus; futuro, como legendus. ${ }^{47}$

As significações dos particípios em que consistem? É que do verbo ativo vêm dois particípios, um presente e um futuro, como legens, lecturus; do passivo dois, um pretérito e um futuro, como lectus, legendus; do neutro dois, assim como do ativo, um presente e um futuro, como stans, staturus; do depoente três, um presente, um pretérito e um futuro, como loquens, locutus, locuturus; do comum quatro, um presente, um pretérito e dois futuros, como criminans, criminatus, criminaturus, criminandus. ${ }^{48}$

Os números dos particípios são quantos? Dois. Quais? Singular, como hic legens; plural, como hi legentes. ${ }^{49}$

As figuras dos particípios são quantas? Duas. Quais? Simples, como legens; composta, como neglegens.

Dê a declinação do particípio. ${ }^{50}$

45 No original, recipit. O mesmo termo se encontra no tratado dos pronomes (cf. n. 11).

46 Os exemplos se traduzem, respectivamente, por: "o que foi lido"; "a que foi lida"; "o que foi lido" (neutro); "o que lê", "a que lê", "o que lê" (neutro).

47 Os exemplos se traduzem, respectivamente, por: "que lê", "que foi lido", "que será lido".

48 Os exemplos se traduzem, respectivamente, por: "que lê", "que há de ler"; "que foi lido", "que será lido"; "que fica”, "que há de ficar"; "que fala", "que falou”, "que há de falar"; "que acusa”, "que foi acusado", "que há de acusar", "que há de ser acusado”.

49 Os exemplos se traduzem, respectivamente, por: "o que lê"; "os que leem".

50 Sobre o significado deste imperativo, cf. n. 38. 
Legens, particípio que vem do verbo ativo, de tempo presente, gênero universal, número singular, figura simples, casos nominativo, acusativo e vocativo, que será declinado assim:

nom. hic e haec e hoc legens

gen. huius legentis

dat. huic legenti

acus. hunc e hanc legentem e hoc legens

voc. olegens

abl. ab hoc e ab hac e ab hoc legente ou legenti e no plural, nom. hi e hae legentes e haec legentia

gen. horum e harum e horum legentium

dat. his legentibus

acus. hos e has legentes e haec legentia

voc. 0 legentes e 0 legentia

abl. ab his legentibus

Lecturus lectura lecturum, particípios que vêm do verbo ativo, de tempo futuro, gêneros masculino, feminino e neutro, número singular, figura simples, casos nominativo e vocativo, que serão declinados assim:
nom. lecturus lectura lecturum
e no plural, nom. lecturi lecturae lectura
gen. lecturi lecturae lecturi
gen. lecturorum lecturarum lecturorum
dat. lecturo lecturae lecturo
dat. lecturis
acus. lecturum lecturam lecturum
acus. lecturos lecturas lectura
voc. lecture lectura lecturum
voc. lecturi lecturae lectura
abl. ab hoc lecturo ab hac lectura ab hoc lecturo
abl. ab his lecturis

Lectus lecta lectum, particípios que vêm do verbo passivo, de tempo pretérito, gêneros masculino, feminino e neutro, número singular, figura simples, casos nominativo e vocativo, que serão declinados assim:

nom. lectus lecta lectum

gen. lecti lectae lecti

dat. lecto lectae lecto

acus. lectum lectam lectum

voc. lecte lecta lectum

abl. ab hoc lecto ab hac lecta ab hoc lecto e no plural, nom. lecti lectae lecta

gen. lectorum lectarum lectorum

dat. lectis

acus. lectos lectas lecta

voc. lecti lectae lecta

abl. ab his lectis

Legendus legenda legendum, particípios que vêm do verbo passivo, de tempo futuro, gêneros masculino, feminino e neutro, número singular, figura simples, casos nominativo e vocativo, que serão declinados assim: 
nom. legendus legenda legendum

gen. legendi legendae legendi

dat. legendo legendae legendo

acus. legendum legendam legendum

voc. legende legenda legendum

abl. ab hoc legendo ab hac legenda ab hoc legendo e no plural, nom. legendi legendae legenda

gen. legendorum legendarum legendorum

dat. legendis

acus. legendos legendas legenda

voc. legendi legendae legenda

abl. ab his legendis

\section{Sobre a conjunção}

Conjunção é o quê? É a parte da oração que conecta e ordena a sentença. A conjunção tem quantos acidentes? Três. Quais? Propriedade, figura e ordem.

A propriedade das conjunções tem quantas espécies? Cinco. Quais? Copulativas, disjuntivas, expletivas, causais e racionais.

Dê as copulativas: et que at atque ac ast. ${ }^{51}$
Dê as disjuntivas: aut ue uel ne nec neque. ${ }^{52}$
Dê as expletivas: quidem equidem saltim uidelicet quamquam quamuis
quoque autem porro porro autem tamen. ${ }^{53}$

51 As copulativas são aquelas que conectam "palavras e sentidos” (SÉRVIO 4.418.7-8), isto é, que tornam a oração coesa no nível da expressão associando termos compatíveis ou, ao menos, não excludentes (LALlot 1985:95). Uma vez que a conjunção possui um significado apenas funcional, os exemplos são difíceis de traduzir individualmente; a lista fornecida recobre equivalentes de "e" (et, que) e de "mas" (at, atque, ac, ast).

52 Disjuntivas são aquelas que conectam as palavras mas desconectam o sentido ([SÉRGIO] 4.418.9-12), isto é, que tornam a oração coesa no nível da expressão mas dissociam os termos no âmbito do significado, na medida em que "a existência de um termo corresponde à exclusão dos demais" (LALlot 1985: 95). A lista de exemplos recobre equivalentes de "ou" (aut, ue, uel) e de "nem" (ne, nec, neque).

53 Conjunções expletivas são assim chamadas porque complementam o sentido (sensum explent): "se alguém diz, 'faça isto!' (hoc fac), te exorta a fazer uma coisa quando talvez estejas fazendo outras; já se alguém diz, 'faça pelo menos isto!' (saltem hoc facito), fica implícito que não estavas fazendo nada” (POMPEIo 5.266.10ss). Atualmente, os dicionários e gramáticas classificam como advérbios a maioria dessas formas; por outro lado, não raro essa espécie de conjunção apresenta "valores puramente discursivos", não possuindo função sintática ou semântica definida (cf. FORTES 2008: 116). Em todo caso, os exemplos recobrem possíveis equivalentes de "na verdade" (quidem, equidem), "ao menos" (saltim), "é claro que" (uidelicet), "ainda que" (quamquam, quamuis), "também” (quoque), "contudo" (autem, porro, porro autem, tamen). 
Dê as causais: si etsi etiamsi si quidem quando quandoquidem quin quin etiam quatenus sin seu sive nam namque ni nisi nisi si si enim etenim ne sed interea licet quamobrem praesertim item itemque ceterum alioquin praeterea. $^{54}$

Dê as racionais: ita itaque enim enimuero quia quapropter quoniam quoniamquidem quippe ergo ideo igitur scilicet propterea idcirco. ${ }^{55}$

As figuras das conjunções são quantas? Duas. Quais? Simples, como nam; composta, como namque.

A ordem das conjunções em que consiste? É que há conjunções prepositivas, como ac, ast, pospositivas, como que, autem, ou comuns, como et, igitur.

54 As conjunções causais são aquelas que exprimem "o motivo que nos leva a fazer algo" (POMPEIO 5.267.18): por exemplo, "se eu mato aquele homem, tomo sua herança" ([SÉrgio] 4.516.26). A lista de exemplos recobre itens que equivalem a diferentes espécies da classificação moderna: condicionais como "se" (si, si quidem, sin, seu, siue, si enim), "se não" (ni, nisi, nisi si); concessivas como "mesmo se" (etsi, etiamsi, licet), "nem mesmo se" (quin, quin etiam); causais como "pois" (nam, namque, etenim), "uma vez que" (quando, quando quidem, quatenus), "por causa de" (quamobrem); finais como "para que não" (ne); temporais como "enquanto" (interea). Não encontramos explicação para o valor causal de sed, praesertim, item, itemque, ceterum, alioquin, praeterea; é possível que sua inclusão se deva à coocorrência dessas partículas com conjunções propriamente ditas, dado seu valor basicamente continuativo ("além disso", "por outro lado", etc.).

55 As racionais são aquelas que indicam "o raciocínio que alguém utiliza para fazer algo" (SÉRvio 4.418.18): por exemplo, "devo matar [aquele homem] sem ser visto, portanto vou me esconder" ([SÉrgio] 4.516.27-8). A lista de exemplos traz conjunções atualmente consideradas conclusivas, como "assim sendo" (ita, itaque), "por isso" (ideo, propterea, idcirco), "portanto" (ergo, igitur); explicativas, como "porque" (quia, quapropter), "já que” (quoniam, quoniamquidem); ou marcadores discursivos, como "de fato" (enim, enimuero), "com efeito" (quippe), "de certo" (scilicet). A semelhança entre certas conjunções racionais e causais não é ignorada pelos gramáticos latinos: esta é "uma distinção difícil, que pertence mais a filósofos e oradores do que a gramaticos" (CLEDÔNIO 5.73.27-8). Tal dificuldade parece ligada a uma mais geral, de que a classificação das conjunções se baseia no uso "que segue o rigor da arte; mas os autores confundiram" (РОMPEIO 5.268.7); o mesmo é atestado por Donato, quando afirma que "se encontram conjunções empregadas no lugar de outras conjunções, com propriedade trocada” (DonATO 648.1-2). Eis um indício de que muitas classificações da gramática antiga dizem respeito mais a funções do que a formas. 


\section{Sobre a preposição}

Preposição é o quê? É a parte da oração que, preposta às outras partes da oração, complementa, altera ou diminui a significação delas. ${ }^{56} \mathrm{~A}$ preposição tem quantos acidentes? Um. Qual? Somente caso. Quantos? Dois. Quais? Acusativo e ablativo.

Dê as preposições de acusativo:

$\begin{array}{llllll}\text { ad } & \text { citra } & \text { extra } & \text { ob } & \text { post } & \text { supra } \\ \text { apud } & \text { circum } & \text { inter } & \text { pone } & \text { trans } & \text { usque } \\ \text { ante } & \text { circa } & \text { intra } & \text { per } & \text { ultra } & \text { penes } \\ \text { aduersum } & \text { contra } & \text { infra } & \text { prope } & \text { praeter } & \\ \text { cis } & \text { erga } & \text { iuxta } & \text { secundum } & \text { propter } & \end{array}$

Como? Dizemos: ${ }^{57}$

$\begin{array}{llll}\text { ad patrem } & \text { circa templum } & \text { iuxta macellum } & \text { trans ripam } \\ \text { apud uillam } & \text { contra hostem } & \text { ob augurium } & \text { ultra fines } \\ \text { ante aedes } & \text { erga propinquos } & \text { pone tribunal } & \text { praeter officium } \\ \text { aduersum inimicos } & \text { extra terminos } & \text { per parietem } & \text { propter rem } \\ \text { cis Renum } & \text { inter naues } & \text { prope fenestram } & \text { supra caelum } \\ \text { citra forum } & \text { intra moenia } & \text { secundum fores } & \text { usque Oceanum } \\ \text { circum uicinos } & \text { infra tectum } & \text { post tergum } & \text { penes arbitros }\end{array}$

56 Os comentadores ilustram as capacidades da preposição: de complementação, e.g. praeclarus ("clarus é o que manifesta claridade, praeclarus o que manifesta muita claridade", JuLiano 104.1-3); de alteração, e.g. infelix ("infeliz", palavra em que a preposição "inverte a significação do composto", CLEDÔNIO 5.25.6); de diminuição, e.g. subdolus ("que é menos do que dolus", POMPEIO 5.271.23-4; exemplo em português é "subnutrido"). Note que os exemplos são todos casos de prefixação na classificação atual; a reunião de preposições e prefixos em uma mesma classe pode se explicar pelo fato de que em latim a maior parte dessas formas é coincidente; daí a definição se referir a "outras partes da oração" indistintamente, pois a construção preposicional propriamente dita se dá apenas diante de palavras com flexão de caso.

57 Os exemplos a seguir se traduzem, respectivamente, por: "para a casa do pai", "perto da propriedade, "diante da casa, "contra os adversários, "deste lado do Reno", "antes do fórum", "em torno dos vizinhos", "em volta do templo", "contra o inimigo", "em relação aos parentes", "além dos limites", "entre as naus", "no interior das muralhas", "abaixo do teto", "junto ao mercado", "por causa da profecia", "atrás da tribuna", "através da parede", "perto da janela", "ao longo da porta", "pelas costas", "do outro lado da margem", "depois das fronteiras", "além do dever", "por causa do assunto", "acima do céu", "até o Oceano", "nas mãos dos juízes". É evidente que a falta do contexto confere a tais equivalências o caráter de uma entre muitas possibilidades. 
Dê as preposições de ablativo:

$\begin{array}{lllll}a & \text { cum } & \text { de } & \text { pro } & \text { sine } \\ \text { ab } & \text { coram } & e & \text { prae } & \text { absque } \\ \text { abs } & \text { clam } & \text { ex } & \text { palam } & \text { tenus }\end{array}$

Como? Dizemos: ${ }^{58}$

$\begin{array}{llll}\text { a domo } & \text { coram testibus } & \text { ex praefectura } & \text { sine labore } \\ \text { ab homine } & \text { clam custodibus } & \text { pro clientibus } & \text { absque iniuria } \\ \text { abs quolibet } & \text { de foro } & \text { prae timore } & \text { tenus pube } \\ \text { cum exercitu } & \text { e iure } & \text { palam omnibus } & \end{array}$

* que nós dizemos pube tenus. ${ }^{59}$

Dê as preposições de dois casos: in, sub, super, subter. Quando in e sub dependem do acusativo? Quando o significado é que nós ou qualquer um vai, foi ou irá para o lugar. Quando do ablativo? Quando o significado é que ou nós ou qualquer um está, esteve ou estará no lugar:

- in com acusativo: "itur in antiquam siluam" 60

- in com ablativo: "stans celsa in puppi" 61

- sub com acusativo: "postesque sub ipsos / nituntur gradibus" 62

- sub com ablativo: "arma sub aduersa posuit radiantia quercu" 63

Super tem que valor? Quando significa lugar, depende mais do acusativo que do ablativo; quando fazemos referência a alguém, apenas do ablativo, como "multa super Priamo rogitans" ${ }^{64}$ isto é, de Priamo. In tem que valor? Depende ainda do acusativo quando signi-

58 Os exemplos a seguir podem se traduzir, respectivamente, por: "de casa”, "pelo homem", "por quem quer que seja”, "com exército", "perante as testemunhas", "às escondidas dos guardas", "a partir da praça”, "conforme o direito", "de dentro da prefeitura”, "em defesa dos clientes", "por causa do medo", "na frente de todos", "sem esforço", "sem ofensa", "até o púbis".

59 Como em Virgílio Aeneis 3.427.

60 "Vai-se à antiga floresta" (Virgílio Aeneis 6.179).

61 "Estando no alto da popa" (Virgílio Aeneis 3.527).

62 "E, por sob os próprios batentes, procuram subir os degraus" (Virgílio Aeneis 2.442-3).

63 "Colocou armas radiantes sob o carvalho em frente" (Virgílio Aeneis 8.616).

64 "Muitas coisas indagando sobre Príamo" (Virgílio Aeneis 1.750). 
fica "contra", como in adulterum, in desertorem. ${ }^{65} \mathrm{E}$ subter tem que valor? $\mathrm{O}$ mesmo dos exemplos anteriores que significam "para o lugar" e "no lugar". ${ }^{66}$

Quais são as preposições que dependem das palavras e não podem se separar? Estas: di, dis, re, se, am, con. Como? Pois dizemos diduco, distraho, recipio, secubo, amplector, congredior. ${ }^{67}$ Quais são as que não podem se juntar? Estas: apud, penes. Quais se juntam e se separam? Todas as outras.

\title{
9. Sobre a interjeição
}

Interjeição é o quê? É a parte da oração que significa um afeto da mente por meio de uma voz confusa. A interjeição tem que acidente? Apenas significação. Em que consiste a significação da interjeição? É que ou significamos alegria, como euax, ou dor, como heu, ou admiração, como papae, ou medo, como attat, entre outras semelhantes.

\author{
Tradução de \\ LUCAS CONSOLIN DEZOTTI \\ Faculdade de Filosofia, Letras e Ciências Humanas \\ Universidade de São Paulo
}

65 Respectivamente, “contra o adúltero”, “contra o desertor”. Esse uso é muito comum na linguagem jurídica, especialmente em peças de acusação (como os discursos de Cícero in Verrem, in Catilinam, etc.).

66 mesmo critério movimento/repouso é usado por Cledônio para distinguir entre ad e apud: de fato, "ad é itinerária, apud é local" (5.25.12-3).

67 Exemplos de prefixação que se traduzem, respectivamente, por: "disperso", "destrincho", "recebo", "durmo sozinho", "abraço", "vou ao encontro". 